\title{
Assessment of Knowledge and Attitude of Parents Towards the Allergy and Bronchial Asthma in Their Children
}

\author{
Gaude Gajanan ${ }^{1 *}$, Vinay Sandeep Padbidri ${ }^{2}$, Alisha Chaudhury ${ }^{1}$
}

\section{Gaude Gajanan ${ }^{1 *}$, Vinay Sandeep Padbidri², Alisha Chaudhury ${ }^{1}$}

'Department of Pulmonary Medicine, KLE University's J. N. Medical College, Belgaum, INDIA.

2Department of Paediatrics, Karnataka Institute of Medical Sciences, Hubbali, INDIA.

\section{Correspondence}

Dr. Gajanan Gaude S, Professor Department of Pulmonary Medicine, KLE University's J. N. Medical College, Belgaum, INDIA.

Email: gsgaude922@gmail.com

\section{History}

- Submission Date: 03-09-15:

- Review completed: 18-06-16;

- Accepted Date: 22-06-16.

DOI : 10.5530/ijmedph.2016.3.5

Article Available online

http://www.ijmedph.org

Copyright

(C) 2016 Phcog.Net. This is an open-access article distributed under the terms of the Creative Commons Attribution 4.0 International license.

\begin{abstract}
Introduction: Bronchial asthma is a chronic airway disease that affects a significant children population with limitation of their activities and school absenteeism. The objective of the present study was to assess the knowledge and attitude of the parents towards the disease in their children.
\end{abstract}

Materials and Methods: A hospital based cross-sectional study was conducted in Pulmonary Medicine department in a tertiary care hospital with diagnosed asthmatic children and their parents were enrolled. Two questionnaire one comprising clinical aspects including etiology and other regarding knowledge and attitude among parents regarding asthma were administered.

Results: A total of 150 children with confirmed diagnosis of asthma were included in this study. On an average, each child had already visited 3 doctors prior to coming to us. Out of 150 patients, $77 \%$ parents were ignorant regarding disease etiology, $41 \%$ parents thought that their disease is fatal, $54 \%$ parents were reluctant to accept the diagnosis of asthma. Regarding precipitating factors, $46 \%$ parents attributed the disease exacerbations due to multiple causes. Almost half of the parents had sought alternative for of medicine for management of disease with nearly one-third opting for homeopathic treatment. Oral medications were preferred by $79 \%$ patients, while inhalers were used by only $21 \%$ of children. The compliance rate in using inhalation therapy in children was very low.

Conclusion: Asthma awareness among parents of asthmatic children is inadequate. Controller medications and aerosol therapy is underused and unnecessarily blamed. Awareness raising strategies are needed in community. Patient education program should augment awareness; eliminate social stigma, and misconcepts in the community regarding bronchial asthma.

Key words: Asthma in children, Asthma knowledge, Attitude, Practices, Parents.

\section{INTRODUCTION}

Bronchial asthma is one of the most common chronic diseases among children and adolescents. ${ }^{1,2}$ In recent decades, the prevalence of asthma and morbidity are increasing. It is a common cause of school absenteeism and limitation of activity in children. A recent study has reported a current asthma prevalence of $11.8 \%$ in children aged 13 to 14 years old. ${ }^{3}$ The impact of asthma in children depends on complex interaction between disease severity, reaction of children towards disease, treatment efficiency, social roles, and social environment. ${ }^{4}$ Bronchial asthma, if a remains uncontrolled during childhood leads to continuous symptoms leading to limitations in physical activities and it can lead to development of chronic obstructive pulmonary disease during the later years of life. ${ }^{5}$ Hence proper control of the disease is of paramount importance during this period to prevent the morbidity due to asthma. Bronchial asthma in children makes it more difficult for control due to several reasons. It promotes continued dependency on parents because they customarily share the long term management of the disease. ${ }^{6}$
Similarly, the limitation of physical activity such as sport and dancing, and the need to take treatment make them different from their peers. ${ }^{7}$ Additionally, mode of administration via various inhalation devices makes it cumbersome for the children to take the medicines regularly. ${ }^{8}$ Also, children become fussy about the daily intake of the medicines and tend to skip them regularly. Under diagnosis and under treatment of asthma are frequent in children and many times this is being treated as upper respiratory tract infections. This may be partly due to a lack of perception of the disease leading to underestimation of its severity, tendency to deny the symptoms and reluctance to seek medical advice. ${ }^{9}$

Compliance with therapeutic regimens in asthma, especially in adolescence, is low. ${ }^{10}$ Education has been cited as an important component of any asthma management strategy, by improving asthma knowledge and changing behavior. ${ }^{1}$ Knowledge, attitudes, and beliefs of the parents towards bronchial asthma are recognized as being major determinants of health behavior. Currently there is little awareness about asthma in most of the developing countries, including India. Keeping in mind the fact that more
Cite this article : Gajanan G, Padbidri VS, Chaudhury A. Assessment of Knowledge and Attitude of Parents Towards the Allergy and Bronchial Asthma in Their Children. Inter. J. Med. Public Health, 2016; 6(3):121-5. 
and more people are now suffering from this disease, this lack of awareness is unfortunate. The fact that parents and patients of asthma do not have adequate knowledge about asthma, may lead to delays in instituting proper treatment and hence lead to a higher morbidity and mortality. The objective of this study was to obtain baseline information regarding asthma awareness among the parents of asthmatic children in a Indian community. How far removed are these perceptions from scientific truth and how serious could their repercussions be on the morbidity and mortality caused by the disease? In order to answer these questions, we conducted a survey of the parents of asthmatic children visiting the tertiary care hospital over a period of 18 months to evaluate their perceptions about the disease among their children.

\section{Objectives}

To assess the knowledge on bronchial asthma disease among the parents of children diagnosed from this condition.

To assess the parent's attitude towards this disease and treatments options available among children with bronchial asthma.

\section{MATERIALS AND METHODS}

Population: Patients with bronchial asthma in children between age group of 5-12 years attending Pulmonary Medicine department in a tertiary care hospital.

The present study was a hospital based cross-sectional study conducted in a tertiary care hospital from January 2014 to June 2015. Sample size taken was 150 according to formula $\mathrm{n}=\mathrm{z} 21-\alpha / 2 \mathrm{P}(1-\mathrm{P}) / \mathrm{d} 2$.

Sample size: The sample consisted of 150 children with asthma and their parents. All the eligible children and their parents were included in the analysis since this was a cross-sectional study for duration of 18 months.

Methodology: In the present study, children of bronchial asthma attending out and in-patient services of Department of Pulmonary Medicine, KLES Dr. Prabhakar Kore Hospital and MRC, Belgaum, India, which is a teaching and tertiary care referral hospital, were evaluated during January 2014 to June 2015. Children between age group of 5-12 years with diagnosis of bronchial asthma were included in the study. Cases consisted of all the consecutive patients with the diagnosis of bronchial asthma as defined below. Cases having other significant bronchopulmonary diseases associated with asthma, for example, tuberculosis, bronchiectasis, viral infections, bronchiolitis, children less than 5 years and parents not willing to participate in the study were excluded from the study.

Diagnosis of asthma in selected was based upon following criteria. ${ }^{11}$ Consider asthma if any of the indicator is present: Wheezing, high pitched whistling sound when breathing out with history of any of the following: Course worse particularly at night, recurrent wheeze, recurrent difficult breathing, recurrent chest tightness, family history of any allergy or bronchial asthma. The patients were evaluated for confirmation of diagnosis of bronchial asthma with the help of history, examination, and spirometry before and after bronchodilators inhalation.

An easily comprehensible questionnaire was designed; most questions were closed, with yes or no answers, although one was open ended. The questionnaire was designed to obtain information regarding the parent's perception of aetiology, triggers, asthma symptoms and effectiveness of treatment of asthma with focus on aerosol therapy, which included metered dose inhalers (MDI), dry powder inhalers (DPI), and nebulizer therapy. The patients were asked to identify and describe possible causes of asthma with no limit being placed on the number of responses. No attempt was made to correct a wrong answer or response until the completion of the interview. The open ended question dealt with the parent's personal perception of the best possible management for asthma.
From the detailed questionnaire, the following measurements were made for the study: i) Asthma knowledge: For assessing asthma knowledge of the parents, the following questions were asked in detail: knowledge regarding asthma in their child; familiarity with the symptoms and characteristics of the disease; sport and asthma relationship, on impact of asthma in school; absenteeism from school due to asthma and treatment options available. We have tried to analyze various treatment modalities of treatment of asthma, allopathy, homeopathy or ayurvedic. Also focus was given to the various types of aerosol therapy, and the parent's perceptions regarding this aerosol therapy. Response options were presented as true/false and unsure.

ii) Asthma attitudes: Asthma attitude was assessed by using Gibson et al. ${ }^{12}$ questionnaire (15 questions) that consists of four domains. The domains assessed were tolerance towards asthmatics (eight questions), locus of internal control based on the concept of the degree to which a person believes that their own decisions and actions influence their asthma (two questions), locus of external control or "powerful others" based on the influence of important external people such as a doctor or teacher in their asthma management (three questions) and chance (two questions). Responses were presented as six point scale for parents, ranging from "strongly agree" (scored as 1), to "strongly disagree" (maximum score). An average score was allocated to each domain. Higher scores represent stronger attitudes in the domains assessed. The Institutional Ethics and Review Board approved the study.

\section{Statistical Data Analysis}

Statistical analysis was performed using SPSS Software version 10 . Descriptive statistics were calculated. Mean, median, standard deviation and range were calculated for qualitative variables, and frequencies and percentages were calculated for qualitative variables as mentioned above.

\section{RESULTS}

\section{Demographic characteristics}

The mean age of patients in our study was $9.50( \pm 2.3)$ years with slight male preponderance (M:F 1.54). The mean duration of illness was 3.75 $( \pm 1.2)$ years. Mean age of onset of disease of asthma was $5.7( \pm 2.1)$ years. The ratio of urban to rural population was 1.19:1.

Knowledge about etiology and the disease: Out of 150 patients, more than two-third of the parents did not know that their child is suffering from bronchial asthma disease and all of them had come to know of the diagnosis only at our centre. Only $20 \%$ of the parents were aware about the diagnosis of bronchial asthma in their child. In this study, it was observed that parents of asthmatic child identify the disease as breathlessness (around $76 \% \pm 12 \%$ ) and recurrent attacks of cough $(65 \% \pm 16 \%)$. Another $14.4 \%( \pm 9 \%)$ of parents attribute it to wheezing while $41.3 \%( \pm 11.2 \%)$ patients claim it to be recurrent cold and cough. About $30.7 \%( \pm 9.9 \%)$ of parents believe it to be some kind of allergy or associated with some allergic cause. It was also observed that mothers of children had better perception of the symptoms than the fathers, even though their educational level was lower than the fathers.

Regarding precipitating factors, $46 \%( \pm 13.2 \%)$ of parents could not relate to any cause or factors triggering their disease. Out of remaining 81 parents who were aware of their triggers, $58(71.6 \%)$ parents used to avoid them. Parents had some knowledge about triggering factors in the food items (Table 1$)$. About $87 \%( \pm 17.5 \%)$ of the parents considered respiratory tract infections as precipitating factor for asthma, while $13 \%( \pm 6.9 \%)$ did not know whether infections can precipitate asthma or not. Another $31.3 \%( \pm 9.7 \%)$ parents told that the respiratory symptoms get exacerbated during the seasonal change, especially during winter climate. Dust was recognized as precipitating factor by $70 \%( \pm 21.6 \%)$ and smoke by $63 \%( \pm 16.8 \%)$ of the parents. About $37.3 \%( \pm 11.6 \%)$ observed that cold 
Table 1: Parents perceptions about triggering factors for asthma

\begin{tabular}{ccc}
\hline Triggering food/event & No & $\%$ \\
\hline Cold drinks & 56 & 37.3 \\
Fast foods & 46 & 30.6 \\
Egg & 35 & 23.3 \\
Oily foods & 31 & 20.6 \\
Bakery items & 29 & 19.3 \\
Rice & 17 & 11.3 \\
Multiple & 69 & 46.0 \\
Change of climatic conditions & 47 & 31.3 \\
\hline
\end{tabular}

Table 2: Use of Alternative system of Medicine for Asthma ( $n=108 ; 72 \%$, Multiple answers)

\begin{tabular}{ccc}
\hline Alternative system of Treatment & No & $\%$ \\
\hline Homeopathic & 49 & 32.7 \\
Ayurvedic & 33 & 22.0 \\
Herbal & 21 & 14.0 \\
Fish treatment & 12 & 6.0 \\
Acupuncture & 6 & 4.0 \\
Naturopathy & 4 & 2.7 \\
\hline
\end{tabular}

Table 3: Parent's Attitude towards Asthma disease

\begin{tabular}{ccc}
\hline Patterns of attitude & No & $\%$ \\
\hline $\begin{array}{c}\text { Child does not suffer from } \\
\text { bronchial asthma }\end{array}$ & 81 & 54.0 \\
Child is having only allergy & 46 & 30.7 \\
Someone with asthma should not use inhalers in class & 65 & 43.3 \\
Asthmatics are less competent at physical sports & 71 & 47.3 \\
Teachers have a negative attitude to students with asthma & 49 & 32.7 \\
Teachers are worried about taking someone with asthma on & 35 & 23.3 \\
$\quad$ school trips & & \\
Children with asthma should not play with other children & 29 & 19.3 \\
\hline
\end{tabular}

Table 4: Reasons for non-usage of Inhaler therapy in Asthma

\begin{tabular}{ccc}
\hline Reasons & No & $\%$ \\
\hline Cost of medications & 18 & 12.0 \\
Forgetfulness/Complacency & 26 & 17.3 \\
Dislike of medications & 33 & 22.0 \\
Cultural issues & 21 & 14.0 \\
Attitude towards ill health & 36 & 24.0 \\
Awkward regimens & 29 & 19.3 \\
Poor supervision training/follow up & 26 & 17.3 \\
Distant pharmacy & 9 & 6.0 \\
Difficult to carry & 13 & 8.6 \\
Anger about condition and follow up & 29 & 19.3 \\
Stigmatization & 37 & 24.6 \\
Difficulty with inhaler devices & 27 & 18.0 \\
Side effects & 28 & 18.6 \\
Lack of response & 21 & 14.0 \\
Others & 11 & 7.3 \\
\hline
\end{tabular}

drinks aggravated the symptoms in their child, while $46 \%$ (9.8\%) identified multiple items to be the triggering event. Only $20 \%( \pm 8.8 \%)$ parents could recognize house mites as precipitating factor while $28 \%( \pm 6.5 \%)$ thought that pollens can precipitate asthma.

Regarding the belief associated with bronchial asthma, almost 77\% $( \pm 17.8 \%)$ of parents were ignorant regarding etiology of their disease; $30.7 \%( \pm 7.5 \%)$ parents believed it to be of allergic etiology; $18.5 \%$ $( \pm 6.4 \%)$ parents attribute it to genetic; $5.6 \%( \pm 1.6 \%)$ patients had the misconception that it is the curse of God. Regarding the fate of disease, majority of parents $(41 \% \pm 2.5 \%)$ were under the wrong belief that asthma is fatal in outcome, while $36.4 \%( \pm 6.8 \%)$ parents believed that their disease is absolutely curable. Only $22.6 \%( \pm 4.7 \%)$ parents believed that their disease is preventable and can be controlled. Almost half of the parents had sought the help of alternative system of medicine for the control of the disease, with nearly one-third opting for homeopathic treatment before coming to our department (Table 2).

\section{Asthma attitudes and Knowledge about Management}

Asthma attitude was measured by question are as assessed by Gibson et al. ${ }^{12}$ The responses were presented as six point scale for parents, ranging from "strongly agree" (scored as 1), to "strongly disagree" (maximum score). An average score was allocated to each domain. There are lots of misconceptions about asthma in society and especially among the parents if their child is having asthma. More than half of the parents denied that their child is suffering from asthma, and emphasized that he/she is just having allergic symptoms. About $43.3 \%$ (95\% CI 1.00 to 1.006 ) believed that their child should not use the inhaler and it would become a habit permanently. Another $32.7 \%$ (95\% CI 0.92 to 1.05) said that the teachers have a negative attitude towards their child due to continuous respiratory symptoms and nearly $23.3 \%$ (95\% CI 0.89 to 1.05 ) of teachers are worried to take their child to school trips or excursions due to asthma symptoms. Nearly $19.3 \%$ parents ( $95 \%$ CI 0.99 to 1.03 ) thought that their children with asthmatic symptoms should not play with other children (Table 3).

On an average, each child had already visited 3 doctors prior to coming to our institution. Oral medications in the form of tablets, capsule, and syrups remained the preferred mode of drug administration in $79 \%$ $( \pm 18.6 \%)$ patients. This was followed by inhalational route in only $21 \%$ $( \pm 4.8 \%)$ patients. Among inhaled therapy, 58\% $( \pm 11.6 \%)$ patients preferred dry powder inhalers and $42 \%( \pm 9.7 \%)$ patients preferred metered dose inhalers. Out of 150 patients, 63 children were using inhalers at the time of study. Half of the parents i.e. $50 \%$ know about usefulness of aerosol therapy for asthma while rest of $50 \%$ does not. Reasons for reluctance to inhaled therapy were different: some were not advised by the doctor, some find it difficult to use, and 10\% think that inhaled therapy is harmful or addictive. Even among $21 \%$ of children who were using inhalation therapy, the compliance rate was very low. Table 4 gives all the reasons for discontinuing the inhalation therapy. The most common among these were: attitude towards ill health, stigmatization, and dislike for medications.

In response to the question that which medications do you keep at home for acute bronchospasm, $42 \%$ answered that they don't keep any medication at home. Reasons were different, some lack in knowledge, some cannot afford, some of them found it very dangerous to keep medicines at home and do self medication. Another $24 \%$ kept salbutamol at home, $27 \%$ used anti-allergy for acute exacerbation, while $11 \%$ kept multiple medications.

\section{DISCUSSION}

The present study showed that the parents of asthmatic children still lack adequate knowledge about asthma and have many misconceptions 
regarding disease and its treatment. Many of the parents refuse to accept the diagnosis of asthma and have poor knowledge about the inhalational form of therapy. They have got many misconceptions of inhalers and its usage in everyday practice. Asthma is still a neglected entity unlike other chronic diseases like diabetes mellitus and hypertension. The findings of the present study is similar to that obtained in a recent study done in Islamabad, where it was again observed that the level of awareness regarding asthma was very low among caregivers for asthmatic children. ${ }^{13}$ There is a global problem with asthma management, either under treatment due to ignorance or distorted information/knowledge of patients about their disease. ${ }^{14}$ Asthma is on rise globally and average asthmatic patient is generally ignorant about his ailment and has misconceptions, which needs to be rectified.

Most of our patients, that is, 76 (50\%) were from urban population, but still were ignorant about their disease. Studies have shown that asthma is more prevalent in urban areas than in less polluted areas. ${ }^{15}$ A large numbers of patients (68\%) were unaware about the cause of disease, and were also having various wrong beliefs associated with asthma. Other studies by different authors have reported similar findings. ${ }^{16-18}$ The physicians in our hospital disseminated the knowledge of asthma to parents and accepted that their child had asthma. This reinforces the need for the role that can be played by media, nongovernmental organizations and health workers in heath education regarding asthma. Asthma is still considered like a stigma by the families and proper treatments is not given to the children right from the beginning. As in the present study many considers it just an allergy (30.7\%), and early treatment is not instituted. This leads to progression of the inflammation in the airways leading to progression of the disease.

Due to the poor knowledge about the asthma disease, the parents have lot of anxieties. Anxieties about their disease or treatments leave some asthmatics in an unending cycle of poor disease management, fear, symptoms, and resorting to alternative system of medicine in the hope of getting "cured" of asthma. We also had $72 \%$ parents who tried alternative system of medicine in the hope of getting their disease cured. Studies of Kishan and Singh ${ }^{19}$ and Pradel et al, ${ }^{20}$ also reported that complete trust and positive attitude of the patients towards other therapies for asthma. Similar to our study another study done in Islamabad has reported similar results. ${ }^{21}$ They reported that nearly about $64 \%$ of the patients were ignorant about the etiology of the asthma disease, and 30\% of the patients were reluctant to accept the diagnosis of asthma. It was also observed that patients had become more concerned of their health, with on an average, patient's visits to the physician had increased to 3.2 from the earlier 2.1 doctors.

Parents have several myths regarding asthma disease, triggering factors and treatment. The parents had many misconceptions regarding triggers of asthma. Among them were rice, milk and foods rich in oil. This belief leads to with holding of a wide variety of healthy nutritious foods from growing children, thereby having an adverse effect on their nutritional status and overall growth pattern. These misconceptions need to be clarified so that asthmatic children are not deprived of nutrition unnecessarily. ${ }^{22}$ Very few parents thought that heredity has anything to do with asthma; this was similar to the findings of Hazir et $a^{22}$ and Hsieh and Chiou, ${ }^{23}$ where most of the schoolteachers thought that asthma was an acquired illness.

Attitudes toward adolescent asthmatics denoted tolerance, in the sense of a positive and understanding attitude to a person with asthma. Both teachers and students considered that dominant control of the illness should remain with the individual. These findings indicate that the school environment is receptive to intervention concerning asthma. Teachers" understanding about asthma and sports reflects the widespread belief confirmed in this study, that asthmatic students" performance was lower than that of their peers. This indicates a need for more structured information and training of teachers if their observations during play or games periods are to help identify undiagnosed asthma in teenagers. ${ }^{24}$ Similar findings were observed by Leiria Pinto. ${ }^{13}$ It was found that the attitudes of peers towards asthma were clearly different from those of the students with asthma. The non-asthmatic peers tended to favor a greater role for external influences such as teachers, doctors, and chance in determining health outcomes in asthma.

Even though inhaler therapy has been accepted as first-line therapy in developed countries, the level of acceptance is poor in our country. Only $21 \%$ were using inhalational therapy for the control of asthma. Even among them, more than $60 \%$ patients had discontinued inhalers during the course of their treatment. Surprisingly in one study, ${ }^{25}$ it was observed that inhalers were considered to be inferior to oral drugs by majority of patients $(76.3 \%)$, rotahalers were used less frequently $(12.1 \%)$ as compared to metered dose inhalers (35.1\%). In another study, ${ }^{16}$ it was observed that that majority of patients refused inhaler therapy because they were difficult to use (50.4\%), difficult to carry (48.6\%), habit forming (41.9\%), last resort (38.2\%), and social stigma (36.6\%). A study on the same subject was also done by the Prasad et al ${ }^{15}$ about 10 years back; and after analyzing two studies, ${ }^{15,21}$ it was found that there was some improvement in the level of awareness in the patients. Preference to use inhaled drugs had increased from $5.2 \%$ to $36.42 \%$ patients. These figures clearly reflect that we, as physicians, have been partly successful in creating awareness among general public about this disease. In a study from Malaysia, most of the parents were concerned about the side effects of inhaled medication in addition to the fear of "inhaler dependency". Other concerns voiced by the parents were the cost of inhaled medication and difficulty in using inhalers. ${ }^{26}$ Recently, Gaude et $a{ }^{27}$ has observed that the compliance in bronchial asthma patients was just about $38.6 \%$, and even after health education it improved by another $40 \%$. Hence it is not only the responsibility of the parents, but also the treating physicians should be responsible for proper education regarding the inhalational therapy in bronchial asthma. Only then the compliance will improve and the disease can be controlled to the optimum level. The patient education should be repetitive at every subsequent visit. Hazir et al22 observed that, careers who were handling the asthmatic children, they felt that inhaled medication was more effective in controlling the symptoms of the disease. It could be a result of the fact that most of the children were on inhalation therapy for many months or years, and the beneficial effects of the inhalation therapy were apparent to the careers.

Most of the parents usually try oral therapy in their children for a variable length of time before switching over to inhaled medication. It has been observed that the frequency of acute exacerbations and yearly hospital visits reduced with inhalation therapy. ${ }^{22}$ Children's school attendance also improved. According to the careers, when switched over to inhalation therapy, the children had fewer side effects, such as palpitations, tremors, and headaches. None of the carers found inhalation therapy difficult to administer once demonstrated. This dispels the prevailing concept among medical practitioners that inhalers are not acceptable to most people in our country, as they are considered to be addictive and supposed to be the last resort in the management of the disease. ${ }^{22}$ This is s misnomer that the inhalers are addictive and should be used as last resort. Hence educating the parents play an important role in controlling the asthma disease in the children. Even one study which was conducted in Puerto Rican community, ${ }^{28}$ it was observed that there was no notable difference in the understanding of asthma between people belonging to opposite ends of the economic or education spectrum. Therefore, it is required to target all segments of society, irrespective of socioeconomic or educational status, and to create better awareness about this disease, so that timely medical advice is sought. This will help reduce the morbidity 
associated with childhood asthma, in addition to improving the quality of life of asthmatic patients. Formulation of national programs, conducting continuing medical education programs and frequent reminders, such as newsletters, are initial steps in improving asthma knowledge and awareness in the community. ${ }^{29}$ The dimension of the asthma problem in children and adolescence and its social and economic impact justifies assessing the need for the implementation of asthma education programs in schools. By improving asthma knowledge, clarifying wrong beliefs and promoting the organization in schools of basic medical care in asthma exacerbation, we can certainly contribute to the full integration of asthmatics in school and to reducing the social and economic costs of asthma.

There are certain limitations in this study. Firstly, this is a hospital based study; hence the findings cannot be generalized to the community level. Secondly, sample size is small and larger study is required to know the prevalence of misconceptions in asthma in children. Thirdly, socioeconomic status of the parents was not considered, even though the educational levels were enquired. The socio-economic status of the parents, which can be an important aspect, can influence their knowledge and attitude towards the disease. Lastly, we had used local language questionnaire, which was translated from English language questionnaire, which requires to be validated.

In conclusion, sincere and sustained efforts are required to disseminate knowledge about all aspects of asthma and its management among parents and to dispel their myths and misconception associated with diseases and its therapy. This will help patients to participate in selfmanagement plans and better control of the asthma in their children. Asthma management is incomplete without a good tailored patient and caregiver's education programs and such programs should be able to augment health education and eliminate misconceptions and stigma in community regarding bronchial asthma.

\section{ACKNOWLEDGEMENT}

We are thankful to Medical Director and Chief Executive, KLES Dr. Prabhakar Kore Hospital \& MRC, Belgaum for allowing us to carry out this study and giving permission for publication.

\section{CONFLICT OF INTEREST}

The author have no conflict of interest to declare.

\section{REFERENCES}

1. Sheffer $A L$, et al. Global strategy for asthma management and prevention $N H L-$ BINHO workshop report, 1993. National Institutes of Health. 1995;95:3659.2.

2. Forero R, Bauman A, Young L, Larkin P. Asthma prevalence and management in Australian adolescents: results from three community surveys. J Adolesc Health. 1992;13(8):707-12. http://dx.doi.org/10.1016/1054-139X(92)90068-M

3. Rosado Pinto J, et al. Prevalence of asthma and rhinitis in Portuguese teenagers (ISAAC). Eur Respir J. 1996;9(suppl 23):233S.

4. Suarez-Varela MM, Garcia de Andoin N, Batlles-Garrido J, et al. Geographic variance in the prevalence of asthma symptoms in Spanish children and adolescents. International study of Asthma and Allergies in Childhood (ISSAC) Phase 3, Spain]. Arch Bronchoneumol. 2005;41(12):659-66.

5. Anjan kumar DS, Adepu R, Parthasarathi G, Mahesh PA. Impact of community pharmacist provided patient education in asthma patients on treatment outcomes-A study. Indian J Pharm Educ Res. 2009;43(2):125-33.

6. Taylor WR, Newacheck PW. Impact of childhood asthma on health. Pediatrics.
1992;90(5):657-62. PMid:1408534

7. Organization Mondiale de la Santé. Les jeunes et la santé: defi pour la societéRapport Technique 731. Organisation Mondiale de la Santé 1986; Genève.

8. Price J. The transition of management from childhood to adolescence. Eur Respir Rev. 1997;7:19-23.

9. Lenney W, Wells NEJ, O"Neill BA. Burden of childhood asthma. Eur Respir Rev. 1994;4:4962.

10. Brook U, Shiloh S. Attitudes of asthmatic and nonasthmatic children towards cigarettes and smoking. Clin Pediatr. 1993;32:642-6. http://dx.doi.org/ 10.1177/000992289303201101

11. Global Initiative for Asthma (GINA). Global Strategy for Asthma Management and Prevention. Updated 2014. Available from: http: //www.ginasthma.com (Accessed on

12. Gibson PG, Henry RL, Vimpani, Halliday J. Asthma knowledge, attitudes and quality of life in adolescents. Arch Dis Child. 1995;73(4):321-6. http://dx.doi. org/10.1136/adc.73.4.321; PMid:7492196 PMCid:PMC1511323

13. Leiria Pinto P. Adolescents and school asthma knowledge and attitudes. Allergol Immuno Pathol. 1999;27(5):245-53.

14. Gibson PG, Wilson AJ. The use of continuous quality improvement methods to implement practice guidelines in asthma. J Qual Clin Pract. 1996;16(2):87-102. PMid:8794399

15. Prasad R, Gupta R, Verma SK. A study on perception of patients about bronchial asthma. Indian J Allergy Asthma Immunol. 2003;17(2):85-7.

16. Bedi RS. Knowledge about asthma and its management in asthmatics of rural Punjab. Indian J Tub. 1993;40:153-5.

17. Pacheco $Y$, Zureik M, Dussopt $C$, Thiriet $C$. Patient knowledge of asthma: Results of a national survey in Pneumology. Rev Pneumol Clin. 1999;55(6):353-63. PMid:10685470

18. Shivbalan S, Balasubramanian S, Anandnathan K. What do parents of asthmatic children know about asthma? An indian perspective. Indian J Chest Dis Allied Sci. 2005;47(2):81-7. PMid:15832951

19. Kishan J, Singh A. Knowledge, attitude and practice (KAP) of patients and physician of Bronchial Asthma. Proceedings of XVIII National Congress on Respiratory Diseases, Jalandhar; 1998;pp:6-7.

20. Pradel FG, Hartzema AG, Bush PJ. Asthma self-management: The perspective of children. Patient Educ Couns. 2001;47(6):199-209. http://dx.doi.org/10.1016/ S0738-3991(01)00123-9

21. Sodhi R, Prasad R, Kushwaha R, Kant S, Verma SK and Garg R et al. A study to know the Knowledge, attitude, and practices of patients of bronchial asthma. Int J Med Public Health. 2013;3:159-62. http://dx.doi.org/10.4103/2230-8598. 118959

22. Hazir T, Das C, Piracha F, Waheed B, Azam M. Carers' perception of childhood asthma and its management in a selected Pakistani community. Arch Dis Child. 2002;87(4):287-90. http://dx.doi.org/10.1136/adc.87.4.287; PMid:12243996 PMCid:PMC1763057

23. Hsieh LP, Chiou HH. Comparison of epilepsy and asthma perception among pre-school teachers in Taiwan. Epilepsia. 2001;42(5):647-50. http://dx.doi. org/10.1046/j.1528-1157.2001.39200.x

24. Brook U, Kishon Y. Knowledge and attitude of healthy high school students toward bronchial asthma and asthmatic pupils. Chest. 1993;103(2):405-7. http://dx. doi.org/10.1378/chest.103.2.455

25. Gupta PP, Gupta KB. Awareness about the disease in asthma patients receiving treatment from physicians at different levels. Indian J Chest Dis Allied Sci. 2001;43(2):91-5. PMid:11529414

26. Chan PW, DeBruyne JA. Parental concern towards the use of inhaled therapy in children with chronic asthma. Pediatr Int. 2000;43(2):547-51. http://dx.doi. org/10.1046/j.1442-200x.2000.01278.x

27. Gaude GS, Hattiholi J, Chaudhury A. Role of health education and self-action plan in improving the drug compliance in bronchial asthma. J Fam Med Primary Care. 2014;3(1): 33-8. http://dx.doi.org/10.4103/2249-4863.130269 PMid:24791234 PMCid:PMC4005198

28. Zayas $L E$, Jaen $C R$, Kane M. Exploring lay definitions of asthma and interpersonal barriers to care in a predominantly Puerto Rican, inner city community J Asthma. 1999;36(6):527-37. http://dx.doi.org/10.3109/02770909909054559 ; PMid: 10498048

29. Castanheira JL. Utilizaça o dos Centros de Saúde pelos Adolescentes-um estudo em Lisboa. Rev Port Pediatr. 1987;18: 379-84.

Cite this article : Gajanan G, Padbidri VS, Chaudhury A. Assessment of Knowledge and Attitude of Parents Towards the Allergy and Bronchial Asthma in Their Children. Inter. J. Med. Public Health, 2016; 6(3):121-5. 